\title{
Haxixe: um portal para o horror
}

\author{
Sebastián Torterola Antelo
}

UERJ

\begin{abstract}
Resumo
Como interpretar o que se vê em uma situação de consciência expandida? A primeira vez que o escritor uruguaio Horacio Quiroga prova o haxixe, a substância confronta-o com o horror e a morte. Seguindo a detalhada descrição que o autor faz da experiência, este artigo tenta propor modos de interpretar o material resgatado por ele de sua viagem de treze horas por uma realidade não ordinária. $\mathrm{O}$ trabalho apoia-se, primeiro, nas ferramentas analíticas oferecidas pela psicanálise, em uma tentativa de abordar a questão do ponto de vista da fenomenologia tradicional. Depois, acompanhando certas preocupações filosóficas que propõem a necessidade de uma nova fenomenologia, acode-se a uma análise da perspectiva do inumano: aquilo que existe independentemente da relação entre nós e o mundo, uma existência anônima e inimaginável, que é acessada pelo sujeito, neste caso, por meio de um enteógeno. Essas duas possibilidades de análise estão baseadas em premissas de épocas distantes, mas que se interconectam no artigo para apresentar uma interpretação contemporânea de um conto de 1900.
\end{abstract}

Palavras-chave: horror; enteógeno; haxixe; outside; Quiroga.

\section{Resumen}

¿Cómo interpretar lo que se ve en una situación de conciencia expandida? La primera vez que el escritor uruguayo Horacio Quiroga prueba el hachís, la sustancia lo enfrenta al horror y a la muerte. Siguiendo la detallada descripción de la experiencia realizada por el autor, este artículo intenta proponer formas de interpretar el material rescatado de su viaje de trece horas por una realidad no ordinaria. El trabajo se apoya, primero, en las herramientas analíticas ofrecidas por el psicoanálisis, en un intento de abordar la cuestión desde el punto de vista de la fenomenología tradicional. Luego, acompañando ciertas preocupaciones filosóficas que proponen la necesidad de una nueva fenomenología, se recurre a un análisis desde la perspectiva de lo inhumano: aquello que existe independientemente de la relación entre nosotros y el mundo, una existencia anónima e inimaginable a la que el sujeto accede, en este caso, a través de un enteógeno. Dos posibilidades de análisis basadas en premisas de épocas distintas, pero interconectadas en el artículo para presentar una interpretación contemporánea de un cuento de 1900.

Palabras clave: horror; enteógeno; hachís; outside; Quiroga. 
Porque la cara de la muerte es verde, y la mirada de la muerte es verde, con la aguda bumedad de una hoja de violeta

y su grave color de invierno exasperado.

Pablo Neruda

1. Termo que preferimos por caracterizar especificamente as substâncias psicodislépticas (aquelas que modificam a atividade mental), diferenciandoas das psicoestimulantes (cocaína, êxtase, anfetaminas) e dos psicodepressores (ópio, álcool).

2. Ver ARTAUD, Antonin. Os Tarabumaras, 2000; HUXLEY, Aldous. The Doors of Perception \& Heaven and Hell, 2004; e WASSON, R. Gordon. "Seeking the magic mushroom", Life Magazine, May 13, 1957.
3. QUIROGA, Horacio. "El Haschich”, 1942, p. 167-172.
Em 1900, o escritor uruguaio Horacio Quiroga decide provar haxixe pela primeira vez. O resultado da experiência, acontecida em Montevidéu, aparece descrito em "El haschich", breve e pormenorizada narração do autor sobre a experiência de treze horas (das 15h30min às 4h30min) sob o efeito da substância.

Por que falar sobre o relato de uma viagem psicodélica? Os enteógenos ${ }^{1}$, por sua capacidade de alteração da consciência, abrem as janelas ocultas da casa do ser; transportam seus passageiros para realidades não ordinárias, consciências expandidas e corpos outros; e também brincam com os sentidos, atribuindo cheiros aos sons, instalando visões embaixo das pálpebras e desterrando o tempo e o espaço da percepção. Ao instaurar tal estado de exceção, permitem enxergar novos contornos nos limites do humano. Não são poucos os viajantes que, depois de se verem e verem o mundo da perspectiva nova do enteógeno, voltam diferentes, muitas vezes comparando a experiência com uma revelação mística profundamente transformadora. Isso se explica por alguns efeitos comuns que podemos observar em depoimentos de literatos psiconautas ${ }^{2}$, como a diminuição das barreiras psíquicas que separam consciência e inconsciência e, consequentemente, uma tendência a suspender temporariamente as camadas sociais que compõem o ego individual para ir ao encontro de algo maior, descrito como "a totalidade" ou "o divino", em que se entra em contato com a verdadeira essência das coisas e da própria existência.

De fato, o termo proposto por Robert G. Wasson (enteógeno: que tem um deus dentro) também sugere uma conexão com o divino, introduzindo uma questão fundamental do debate: o conhecimento através da experiência. Para quais destinos viajamos? Que paisagens e seres vemos? A substância nos engana ou nos mostra aspectos reais que permanecem ocultos ao cotidiano? As visões e sensações vêm de fora ou apenas extravasamos o que já estava dentro de nós? As interpretações serão diversas, mas só poderão ser ensaiadas por quem tiver contato direto com a verdade do enteógeno.

Assim como a literatura de viagem tem suscitado o interesse permanente dos povos pelas notícias que ela traz sobre "novos mundos" ainda desconhecidos, vejamos, então, os resultados da aventura interna de Horacio Quiroga, cuja intensidade se resume na primeira linha do texto: "me colocou de frente para a morte" 3 . 


\section{3h30min - Até que enfim iria conhecer o haxixe!}

Ao introduzir o relato, o autor denota um grande entusiasmo pela proximidade do evento, o que permite ver o halo de mistério e sedução gerado pela substância. Como introdução, Quiroga explicita sua experiência anterior com narcóticos como o clorofórmio, o éter e o ópio, todos avaliados muito negativamente pelo autor. Com o haxixe não será diferente, mas, apesar das dificuldades, aparentemente sua vontade de experimentação não diminui.

Neste ponto, é tentador associar Quiroga à figura de Charles Baudelaire, autor de "O poema do haxixe". Ambos admiradores fervorosos de Edgar Poe, com vidas turbulentas e acidentadas, também compartilham uma atividade intensa como viajantes enteogênicos. Aliás, não seria aventurado pensar que o próprio texto de Quiroga seja inspirado nas experiências de Baudelaire em Paris, já que o uruguaio era autodeclarado modernista e admirador do francês.

Baudelaire refere-se a esse aparente paradoxo como o gosto pelo infinito, característica humana que implica, por um lado, na procura de um estado excepcional de espírito e de uma lucidez plena e, por outro, na depravação natural representada pelo vício, que encarna uma fuga obsessiva da realidade, causada pela efemeridade recorrente desse paraíso obtido "de um só golpe"4 por meio das drogas. O francês afirma que esse "veneno excitante" ${ }^{5}$ é um meio do Espírito das Trevas para subjugar a humanidade, causando-lhe o que ele denomina "devastação moral". Tal conclusão, porém, não provém de um ermitão que dedicou sua vida a zelar pela moral de sua época, mas de um boêmio que viveu essa dualidade em primeira pessoa.

É com essa mistura de curiosidade e medo mencionada por Baudelaire que Quiroga entrega-se ao experimento. Além de suas ambivalentes experiências com narcóticos no passado, também contribui para essa dualidade a reputação misteriosa do haxixe, que podemos comprovar no pedido que o amigo farmacêutico faz ao autor: "máxima discrição" . Tal fama é causada em parte pela falta de informação (a intenção de Quiroga é justamente compartilhar o relato para quem não sabe nada sobre a substância ou seus efeitos) e em parte pela origem não ocidental da substância. Muito comum na África muçulmana, no mundo árabe e na Índia, o cânhamo e seus derivados (haxixe, kif, bhang, dawamesk) têm estado historicamente integrados às culturas nativas, com usos tanto terapêuticos e médicos como espirituais ${ }^{7}$.

4. BAUDELAIRE, Charles. "O Poema do Haxixe”, 1998, p. 13.

5. Ibidem, p. 50.

6. QUIROGA, Horacio. "El Haschich", 1942, p. 168.

7. ESCOHOTADO, Antonio. Historia General de las Drogas, 1998. 
8. Ibidem, p. 349.

9. Definido por Baudelaire como a mistura do extrato gorduroso do haxixe com açúcar e diversas fragrâncias, tais como baunilha, pistache, amêndoa ou almíscar; habitualmente consumido com café.
10. RANK, Otto. The Double, 1979.
A ocupação desses territórios pelos europeus a partir da colonização teve como resultado sucessivas proibições do uso do cânhamo, sob o argumento de que este induzia a excessos, delírios e loucura e, em termos gerais, constituía uma ameaça à integridade e à moralidade. Uma dessas proibições foi uma portaria emitida pelo então general Napoleão Bonaparte, no Egito, em 1800, cuja consequência mais saliente foi chamar a atenção (um aspecto bastante comum das proibições) dos franceses para o enteógeno ${ }^{8}$. Nesse grupo, encontrava-se o médico Moreau de Tours, que levou o dawamesk $k^{9}$ para a França e lá formou o "Clube dos haschischiens", com sede no célebre Hotel Pimodan. O grupo era formado por Baudelaire e outros integrantes da classe artística e intelectual parisiense, como Gautier, Delacroix, Nerval, Rimbaud, Hugo e Balzac. Moreau usou o fármaco em suas pesquisas psiquiátricas e, posteriormente, sugeriu o uso do cânhamo para gerar "psicoses de laboratório", termo que também poderia ser aplicado ao depoimento de Quiroga.

\section{Psicodelia e psicanálise}

Feitas essas considerações, num primeiro momento acudimos à psicanálise para uma abordagem inicial da viagem enteogênica a bordo do corpo tomado pelo haxixe. Para isso, estabeleceremos contato direto com o Círculo de Viena através de dois de seus mais ilustres integrantes: Sigmund Freud e Otto Rank.

Podemos relacionar a dualidade que acompanhará Quiroga durante todo o texto com a noção do duplo, que aparece na relação do autor com a expectativa do experimento, combinando o desejo por descobrir os mistérios do haxixe com a aura de respeito que ele provoca, indicando também um medo subjacente que, como veremos, manifestar-se-á pleno e intenso durante a viagem psicodélica: o medo da morte.

Em seu trabalho sobre o duplo e o narcisismo ${ }^{10}$, Otto Rank pesquisa as formas por meio das quais tendemos a excluir a ideia da morte, que é particularmente dolorosa para nossa autoestima, mas que está intrinsecamente associada ao desejo pelo self manifestado no complexo de Narciso. Assim, o mecanismo de defesa para afastar a ideia da morte é estabelecer um equivalente tão distante e prazeroso quanto possível, como forma de compensação. Como sabemos, na fábula de Narciso, o amor próprio exacerbado leva o protagonista à morte. Rank analisa o personagem Dorian Gray, de Oscar Wilde, cuja obsessão por si mesmo é comparável à de Narciso, mas cuja fragilidade mostra o que esse "amor" tem por trás: o simples pensamento de 
imaginar-se velho o faz pensar em suicídio, ou seja, alguma coisa nele parece resistir ao amor-próprio exclusivo. Eis a ambivalência: o medo e o ódio com respeito ao duplo-eu estão conectados com o amor narcísico por ele e com a resistência a esse amor.

No caso de Quiroga, as duas faces do duplo, medo e desejo, estão condensadas na pulsão de morte: o medo está nos fantasmas que lhe aparecem com o haxixe e na sensação de morte inevitável que o autor experimenta; o desejo está na inevitabilidade dos fatos. A decisão de Quiroga de ir até as últimas consequências, ingerindo uma dose exagerada do enteógeno, apesar das advertências do fornecedor, mostra a intensa atração que a ideia do haxixe desperta nele. $\mathrm{O}$ autor não atua com cautela, não toma as precauções médicas necessárias, não considera as suas infelizes experiências anteriores com narcóticos nem o fato de desconhecer os efeitos do haxixe. Não é uma pesquisa científica num ambiente controlado como faria Albert Hofmann com o $\operatorname{LSD}^{11}$, nem um projeto literário calculado e planejado com especialistas, como fez Aldous Huxley ${ }^{12}$ com a mescalina; Quiroga segue o impulso dionisíaco e se entrega por completo, sem pretender objetividade alguma e oferecendo a sua essência na experiência que a posteriori relatará.

A forte presença da morte também é uma característica dominante na vida pessoal de Quiroga, que, durante sua infância, presenciou a trágica morte de seu pai após o disparo acidental de uma espingarda durante um passeio de barco num riacho. Anos depois, sua mãe casou-se novamente, mas, aos seus quinze anos, o padrasto sofreu um derrame cerebral com paralisia, motivo pelo qual este decidiu suicidar-se com um tiro de pistola. Em 1901, um ano depois de escrever "El haschich", a morte bateu a sua porta novamente, levando dois irmãos vítimas de febre tifoide no Chaco argentino; e, em 1902, ao se oferecer para limpar a arma de seu amigo Federico Ferrando, que iria duelar, ele causaria mais um tiro acidental que atingiria o amigo na boca, matando-o instantaneamente. Segundo os relatos da época, a polícia encontrou Quiroga tomado pela culpa tentando se jogar em um poço que existia no quintal da casa para se suicidar ${ }^{13}$.

Tomando algumas ideias centrais de Freud na sua formulação da psicanálise, é possível estabelecer um vínculo claro e direto entre a vida de Quiroga e as visões e sensações experimentadas por ele sob o efeito do haxixe.

\section{5h30min - Monstruosas aranhas verdes}

O caráter sinistro dos acontecimentos mencionados na vida do autor também aparecerá de forma contundente no
11. HOFMANN, Albert. La bistoria del LSD. Cómo descubrí el ácido y qué pasó después en el mundo, 2013.

12. HUXLEY, Aldous. The Doors of Perception \& Heaven and Hell, 2004.

13. ROCCA, Pablo. Cronología bio/ bibliográfica fundamental de Horacio Quiroga, 1994. 
14. QUIROGA, Horacio. "El Haschich”, 1942, p. 167.
15. FREUD, Sigmund. "La represión”, 1980, p. 144. relato do experimento com comparável intensidade. A prosa, repleta de epítetos hiperbólicos ("terrível", "monstruoso", "horror", "atroz"), garante esse sentimento no leitor. Vale a pena evocar um fragmento para reviver os seus efeitos:

...me volví vivamente hacia Brignole, lleno de terror. Fui a hablarle, y su cara se transformó instantáneamente en un monstruo que saltó sobre mí: no una sustitución, sino los rasgos de la cara desvirtuados, la boca agrandada, la cara ensanchada (...) una desmesuración atroz. Todas las transformaciones -mejor: todos los animales- tenían un carácter híbrido, rasgos de éste y de aquél, desfigurados y absolutamente desconocidos. Todos tenían esa facultad abalanzante, y aseguro que es de lo más terrible. ${ }^{14}$

É uma viagem para um mundo pintado de verde, uma confusa floresta mutante onde os humanos são substituídos por animais ferozes e hostis de origem desconhecida e amorfa, que atacam o estranho visitante em múltiplos pontos do corpo com a velocidade de um instante e sem dar chance de proteção. Em momentos particulares, apresentam-se como animais identificáveis, como onças, aranhas ou cobras; e o que é pior: as próprias extremidades dele transformam-se em monstros híbridos que o atacam diretamente nos olhos. No entanto, quando o panorama se torna mais difuso e indeterminado, Quiroga experimenta a sensação mais abrangente de uma "animalidade fantástica".

Assim atacam os "animais do haxixe", que o autor se esforça por definir e caracterizar. Todos eles vêm de fora, do mundo exterior. Mas, a psicoterapia não hesitaria em afirmar: "esses demônios vêm de dentro". De fato, não parece arriscado estabelecer que, aqui, a química, atuando como debilitadora dos mecanismos de defesa do eu, nada mais marca no depoimento de Quiroga do que o retorno do reprimido.

A respeito da repressão, Freud explica que se trata de um mecanismo de defesa engendrado após estabelecer-se uma separação nítida entre atividade consciente e atividade inconsciente da alma. A essência da repressão consiste em rejeitar algo da consciência e mantê-lo afastado dela. Assim, diz ele, repressão e inconsciente são correlativos, funcionando da seguinte maneira: a repressão atua no sistema psíquico do consciente, relegando as pulsões ao plano inconsciente, onde estas se organizam e desenvolvem com maior riqueza, encontrando formas extremas de expressão nas sombras. Aliás, segundo sua experiência clínica, se essas expressões fossem traduzidas e apresentadas ao neurótico, elas não apenas lhe pareceriam alheias, como também o amedrontariam e, inclusive, apresentariam "uma intensidade pulsional extraordinária e perigosa", ${ }^{15}$ resultado de um desdobramento desinibido da fantasia. 
Quiroga está prostrado no seu pequeno apartamento da Cidade Velha, mas o haxixe desencadeia a potência criativa do seu inconsciente. Uma vez fora, o reprimido transforma seu amigo Brignole numa fera predadora, transtroca o seu entorno familiar em ameaças e lança-se sobre o sujeito que o reprimiu clamando vingança. Passada a experiência, ao responsabilizar a química pela criação de todo o terror, o autor escolhe um caminho bem conhecido por ele desde a infância: a negação. $\mathrm{O}$ relato corrobora as palavras de Freud: caso se tratasse apenas do efeito de um estímulo exterior, a fuga seria a solução mais imediata; mas a pulsão impossibilita a fuga, já que o eu não pode escapar de si mesmo. Em Quiroga, o eu escapa-se a cada momento para voltar inexoravelmente à imobilidade, à inevitabilidade dos ataques e à falta de vontade, expressada num desesperado: "não podia querer" ${ }^{\prime 16}$.

No entanto, considerar essa experiência desde uma perspectiva freudiana também nos leva ao conceito de determinismo, que estabelece que nada no plano psíquico obedece ao livre alvedrio ou à casualidade. Isso significa que, se o método psicanalítico for aplicado a atos falhos ou casuais aparentemente desprovidos de propósito (esquecimentos, erros involuntários, deslizes), sempre é possível provar que estes estão motivados e determinados por motivos não consabidos à consciência. $\mathrm{O}$ determinismo também é uma forma de explicar como, até que algum evento mude o padrão (uma sessão de terapia, por exemplo), as ações e decisões na vida do sujeito estarão determinadas por motivações inconscientes que o impelem sem alcançar o plano consciente, num processo cíclico que pode perdurar de geração em geração.

Nessa linha, se atribuirmos as visões do haxixe ao inconsciente de Quiroga, é impossível não relacionar a experiência com os acontecimentos posteriores na vida do escritor, que, depois de matar acidentalmente a Ferrando, muda-se para a Argentina, onde alcança a sua maturidade como escritor morando na selva de Misiones com sua esposa e dois filhos, afastado da civilização, entre jacarés, formigas carnívoras e plantações de erva-mate. Após cinco anos de vida isolada, a esposa Ana María Cirés suicida-se tomando veneno. Em 1937, após ser diagnosticado com câncer gástrico, o próprio Quiroga escolhe a morte por meio do cianureto. Mas, o seu suicídio não acaba com a morte: seus filhos Eglé (em 1939), Darío (em 1954) e Petrona (em 1988) também se suicidam. Buscando explicações para essa sinistra tradição, os biógrafos apontam que o pai de Quiroga era descendente do célebre caudilho argentino Facundo Quiroga, cujo trágico assassinato por adversários políticos na localidade de Barranca Yaco, Córdoba, criou uma lenda em torno de seu nome, imortalizada em um poema de J. L. Borges. O verso que
16. QUIROGA, Horacio. "El Haschich”, 1942, p. 169. 
17. BORGES, Jorge Luis. Obras Completas, 1974, p. 61.
18. Ver LUDUEÑA

ROMANDINI, Fabián. Para

além do principio antrópico. Por uma filosofia do Outside, 2012. dá nome ao poema é citado pelo escritor uruguaio J. C. Onetti ao rememorar a única vez que viu fortuitamente Horacio Quiroga, já doente, esperando um táxi que o levasse para o hospital numa esquina de Buenos Aires: "El general Quiroga va en coche al muere" ${ }^{\prime 17}$.

\section{3h - Via-me na cama, deitado e morrendo}

Mas, não é o objetivo deste artigo tentar um diagnóstico psicoterapêutico do escritor, caindo na imprudência de patologizar as reflexões de um dos melhores escritores de nossa América. Após buscar apoio em conceitos que podemos considerar como pertencentes à fenomenologia tradicional iniciada por Husserl, cujo objeto é o vínculo existente entre o ser humano e o mundo através da consciência, passarei a caracterizar as observações de Quiroga considerando uma proposta fenomenológica não antropocêntrica, formulada por Dylan Trigg como a fenomenologia do horror. A crítica ao antropocentrismo é, justamente, o foco central das propostas mais renovadoras da filosofia atual ${ }^{18}$.

Tal proposta surge como uma crítica à fenomenologia clássica, entendendo que esta apresenta duas limitações. A primeira, de natureza epistemológica, é a impossibilidade de abordar o problema das coisas em si mesmas, independentemente da perspectiva da experiência humana. Dessa forma, ela não permite escapar ao vínculo sujeito-mundo, e a única ideia possível de "exterior" (outside) é um exterior narcisista, enclaustrado pelos limites da percepção humana. Esse sistema, diz Trigg, não é suficiente para nos enfrentarmos com o problema do outro, uma alteridade genuína e verdadeiramente estranha (alien).

A segunda limitação, ética, é que aquela fenomenologia atua com base em uma noção restrita do que significa ser humano, caracterizada por uma homogeneização do corpo e por uma ênfase na unidade e na plenitude, isto é, em vez de problematizar o vínculo ser-mundo, ela parece assumir a missão de reforçar essa relação como um objetivo próprio, o que deve ser questionado. Aliás, essa concepção deixa fora do campo de análise o não humano ou inumano, o desconhecido, o anônimo, o que simplesmente existe "lá fora".

Se a fenomenologia tradicional procura abordar a realidade tal como ela aparece para a consciência, como enfrentar o problema de uma consciência expandida? Parece mais apropriado considerar uma fenomenologia preocupada em explorar os limites da alteridade. 


\section{O horror do corpo}

Um sujeito corpóreo não necessariamente é um sujeito humano. De um momento para outro, o corpo de Quiroga é invadido, hibridiza-se e lança-se contra si mesmo. O inumano surge no humano e submete-o. Um corpo anterior à assimilação cultural, anterior à identidade, desestabiliza a experiência de ser sujeito e estabelece uma experiência não assimilada. É a resposta afetiva do horror, que possibilita a transformação do si mesmo num genuíno outro. É a inumanidade do humano falando por si mesma.

O horror vem menos do desconhecido que do incontrolável, do que invade independentemente da vontade do escritor, que se declara em colapso. Após tentar descrever um sentimento desconhecido com referências familiares, Quiroga deixa escapar um "que sei eu", afirmação de uma presença inumana que não é uma qualidade, nem objeto, nem sujeito. Esse "algo" indefinível se relaciona com o there is postulado por Levinas ${ }^{19}$ : um estado anônimo do ser, uma existência que precede ao nascimento do mundo, algo que pertence às sombras e somente pode ser acessado nas sombras. Por esse motivo, existe fora do plano do sujeito e do objeto, do interior e do exterior, e invade as facetas da existência sem estar aprisionado por elas.

Um exemplo da natureza deste there is pode ser encontrado no advento da noite, que dissolve as formas das coisas e muda o nosso ambiente independentemente da nossa vontade. Quando a noite se instala, já não há "isto" ou "aquilo". Mas, o fundamental é que esse apagamento não nos leva ao nada, a uma ausência da existência, pelo contrário, a escuridão da noite invade como uma inevitável e inquietante presença, na qual participamos quer queiramos, quer não.

O horror do corpo aparece em Quiroga da mesma forma em que, no pôr do sol, o encontro entre luz e sombra confunde os limites do real. Assim como esse jogo de luzes e sombras reveste os contornos do mundo conhecido com uma máscara ambígua que nos paralisa, o humano do escritor mescla-se subitamente com o inumano anônimo, e a sua realidade desfigura-se e hibridiza como se o mundo tivesse aberto as portas ao caos.

Mas, o horror de Quiroga não é essencialmente humano? Levinas responde: é justamente por causa de supervivência desse humano que podemos pensar o inumano. O horror, diz ele, é um movimento que irá despojar a consciência da sua própria subjetividade. Na experiência do escritor, a consciência perde por completo a compostura e a orientação: o eu escapa-se "a cada momento", sente que "deixa a terra", entrar em si custa-lhe "esforços inauditos". No entanto, o sujeito permanece
19. Emmanuel Lévinas, apud. TRIGG, Dylan, The Thing. A Phenomenology of Horror, 2014, p. 48. 
presente, já que, como é afirmado pelo autor, "conserva a inteligência íntegra ainda nos maiores desacertos". No dizer de Trigg, a materialidade do corpo físico sobrevive à dissolução do sujeito pessoal.

Vale notar que, nessa situação, Trigg descreve o lugar ocupado pelo sujeito como um "horizonte de eventos" (também: "ponto de não-retorno"), termo presente na teoria da relatividade de Einstein que se refere a uma fronteira do espaço-tempo de um buraco negro, na qual a força da gravidade é tão forte que nem mesmo a luz pode passar por ela. Por esse motivo, um observador (sujeito) que se encontre de um lado dessa fronteira não pode ser afetado pelos eventos que aconteçam do outro lado.

O mesmo termo em inglês, Event Horizon, é o nome de um filme de Paul Anderson, de 1997, que se apresenta como uma versão de Hollywood de Solaris, clássico de 1972 do diretor russo Andrei Tarkovski. No filme russo, Solaris é um novo planeta recentemente descoberto que está sendo estudado por cientistas que orbitam ao redor dele dentro de uma aeronave. Porém, os cientistas descobrem em Solaris um misterioso mecanismo de defesa que os afeta de uma forma inédita: os piores medos de cada um se materializam e começam a interagir com eles. O horror instala-se dentro da aeronave como resultado da dissolução da fronteira interior/exterior e da impossibilidade de distinguir a realidade de um "outro" estado desconhecido.

No filme de Hollywood (divulgado no Brasil como $O$ enigma do horizonte), o contexto é similar: a tripulação da nave Lewis \& Clark, uma equipe de resgate espacial, recebe a missão de buscar a Event Horizon, uma nave desaparecida sete anos antes que acabara de enviar uma mensagem de socorro. A bordo de Lewis \& Clark, o cientista que inventou Event Horizon revela o motivo do desaparecimento desta: o motor dela é um buraco negro artificial, que permite à nave viajar a uma velocidade inédita, devido a sua capacidade de gerar um atalho ou uma ponte entre o espaço e o tempo. A impossibilidade de saber aonde o buraco negro levou a nave nos últimos sete anos põe os personagens diante do desconhecido inimaginável, que se concretiza quando a nave mostra sinais de ter vida própria e um caráter onipresente. O horror experimentado por eles chega ao máximo ponto quando, recriando o conceito de Solaris, a nave brinca com as percepções dos personagens, revelando, através de imagens e sons, os seus medos e as suas sombras mais secretas, que, em vários casos, guiam os tripulantes diretamente à morte.

Em ambos os filmes, assim como no texto de Quiroga, o desafio dos limites do humano traz a consequência de uma presença/existência que não é possível (porque não é humana), mas que se apresenta palpável e reclama aos personagens a atitude de enfrentá-la como real. 


\section{Um mundo sem humanos}

O desconhecido apresenta-se como uma região particularmente relevante para as novas elaborações da filosofia, que costuma se apoiar na literatura para ganhar impulso. Na sua análise das implicâncias filosóficas da obra de H. P. Lovecraft ${ }^{20}$, Graham Harman afirma que a teoria e a prática humanas são propensas a serem surpreendidas por erupções repentinas de natureza desconhecida, alojadas numa escuridão inacessível ao homem. A importância dessa escuridão inacessível é que ela contém a essência das coisas, já que, seguindo Heidegger, o nosso contato habitual com as coisas é feito através de processos nos quais (ao contrário do postulado pela fenomenologia de Husserl) não há participação da consciência, mas relações assumidas como realidade e que, portanto, permanecem inquestionadas.

No intuito de radicalizar a visão de Heidegger, Harman tomará a sua perspectiva para propor uma fenomenologia não centrada na esfera humana, mas nos objetos. Porém, como vimos, a fenomenologia do horror, que inspira este artigo, dissolve a dicotomia objeto/sujeito ao postular o there is que simplesmente existe no anonimato. Posicionado justamente no cenário de um mundo sem sujeitos nem objetos, a figura de Lovecraft é resgatada um século depois como prenunciação do fim do ser humano e até da própria filosofia, como o escritor de horror que criou uma mitologia que permite "despertar as forças avassaladoras que definem as possibilidades e os limites do homo sapiens"21 numa época de pleno auge do conhecimento (logos).

Mas, de que forma Lovecraft faz essa contribuição? De uma perspectiva inversa à dos filósofos que discutem o ser; em vez de definir os caminhos (ou a impossibilidade) do homem para entrar em contato com as coisas em si mesmas, o escritor americano imagina tudo aquilo que faz parte do não-ser (inacessível), do eminentemente inumano, e coloca isso nas suas histórias de uma forma inquietante. A ressignificação de Lovecraft, das suas sociedades alienígenas e deidades espantosas trazidas aos leitores pelas fendas e entrelinhas da linguagem, adquire valor em nossa época por representar uma ameaça ao sentido, ou seja, o indizível feito literatura, que inspira uma filosofia fora do humano.

Já em Quiroga, o indizível aparece não como resultado da sua imaginação ficcional, mas fruto da experiência direta, como se o haxixe lhe abrisse um portal "real" para o mundo imaginado por Lovecraft nos seus passeios solitários por Providence. O que inquieta em "El haschich" não é a capacidade de Quiroga de desafiar a imaginação com artimanhas retóricas, mas a simples e comovente confissão do seu encontro com o horror. Ele
20. HARMAN, Graham.

Weird Realism. Lovecraft and

Philosophy, 2012.

21. LUDUEÑA ROMANDINI, Fabián. H. P. Lovecraft. A disjunção no Ser, 2013, p. 10. 
existe e está à espreita, é prévio à imaginação e ao corpo humano, extingue e recombina qualidades de sujeito/objeto/animal/ coisa e pode ser comunicado exatamente como: "que sei eu".

\section{Considerações finais}

Ao comparar os argumentos aqui apresentados de uma fenomenologia tradicional com os de uma fenomenologia contemporânea, podemos nos valer de ambos para explicar uma situação de realidade não ordinária, em que o cotidiano se vê invadido por uma presença que o sujeito não reconhece. Para a maioria dos casos de comportamentos afastados de uma suposta normalidade, a psicanálise atribui ao inconsciente a capacidade de guardar e manter latente tudo o que o processo de repressão envia-lhe. Assim, através de ações e falas que muitas vezes aparecem como triviais, podemos adivinhar o que foi reprimido e vê-lo com claridade em manifestações patológicas nos casos clínicos que configuram problemas de saúde mental.

A diferença de perspectiva com esta "nova fenomenologia", aplicada ao texto que aqui analisamos, é que a psicanálise sempre atribuirá a responsabilidade de tudo o que transitar as fronteiras do consciente para o inconsciente (e vice-versa) à intervenção do sujeito. No entanto, a fenomenologia do horror diz: há coisas que nada tem a ver com o sujeito, coisas que são reais, mas que não podemos imaginar (e que, inclusive, negaríamos a sua existência se tivéssemos essa possibilidade) porque são alheias a nós. Para ela, é preciso admitir que há existência além do humano e que nada sabemos dela até que sua presença entre em contato com a nossa. É o momento em que sobrevém o horror.

Como contraponto ao determinismo de Freud, e através da noção de there is de Levinas, é possível considerar essa "existência anônima" que invade Quiroga como um indeterminismo, uma existência não antropocêntrica que reside e se manifesta de maneira completamente alheia ao vínculo ser-mundo e que é acessada pelo escritor por meio do haxixe.

Dessa forma, assim como os mundos imaginados por Lovecraft inspiram uma renovação na filosofia contemporânea, a questão dos enteógenos e seus estados de consciência expandida merece novos capítulos dentro dessa renovação, já que o questionamento de uma história da filosofia excessivamente an-

22. SLOTERDIJK, Peter. Extrañamiento del mundo, 2001, p. 123. tropocentrista está intimamente ligado a questionar a história da cultura como história da abstinência ${ }^{22}$. 


\section{Referências}

BAUDELAIRE, Charles. Paraísos Artificiais. Porto Alegre: L\&PM, 1998.

BORGES, Jorge Luis. Obras Completas. Buenos Aires: Emecé, 1974.

FREUD, Sigmund. Obras Completas, v. VI. Buenos Aires: Amorrortu Editores, 1996. "La represión". In: . Obras Completas, v. 14.

Buenos Aires: Amorrortu Editores, 1980.

ESCOHOTADO, Antonio. Historia general de las drogas. Madrid: Alianza Editorial, 1998.

HARMAN, Graham. Weird Realism. Lovecraft and Philosophy. Zero Books, 2012.

HOFMANN, Albert. La historia del LSD. Cómo descubrí el ácido y qué pasó después en el mundo. Barcelona: Gedisa, 2013.

HUXLEY, Aldous. The Doors of Perception \& Heaven and Hell. New York: Harper, 2004.

LUDUEÑA ROMANDINI, Fabián. H. P. Lovecraft. A disjunção no Ser. Florianópolis: Cultura e Barbárie, 2013. Para além do principio antrópico. Por uma filosofia do

Outside. Desterro: Cultura e Barbárie, 2012.

ANDERSON, Paul. O enigma do horizonte. Paramount, 1997.

Título original: Event Horizon.

ONETTTI, Juan Carlos. "Hijo y padre de la selva". El País, 20 fev. 1987. Disponível em: < http://elpais.com/ diario/1987/02/20/cultura/540774001_850215.html>. Acesso em: 30 abr. 2017.

QUIROGA, Horacio. El crimen del otro y otros cuentos. Montevideo: Claudio García \& Cia. Editores, 1942.

RANK, Otto. The Double. North Carolina: The University of North Carolina Press, 1979.

ROCCA, Pablo. Cronología bio/ bibliográfica fundamental de Horacio Quiroga. Montevideo: Instituto Nacional del Libro, 1994.

SLOTERDIJK, Peter. Extrañamiento del mundo. Valencia: Editorial Pre-textos, 2001. 
TARKOVSKI, Andrei. Solaris. Mokép, 1972. Título original: Coлspuc: Solyaris.

TRIGG, Dylan. The thing. A phenomenology of horror. Winchester: Zero Books, 2014.

WASSON, R. Gordon. El camino a Eleusis. Una solución al enigma de los misterios. México DF: Fondo de Cultura Económica, 1980.

. Seeking the magic mushroom. Life Magazine, May 13, 1957. Disponível em: < http://www.imaginaria.org/wasson/ life.htm>. Acesso em: 30 abr. 2017. 